\title{
ENZYMELESS BIOSENSORS: UMA NOVA ÁREA PARA O DESENVOLVIMENTO DE SENSORES AMPEROMÉTRICOS
}

\author{
Maria Del Pilar Taboada Sotomayor e Lauro Tatsuo Kubota*
}

Departamento de Química Analítica, Instituto de Química, Universidade Estadual de Campinas, CP 6154, 13083-970 Campinas - SP

Recebido em 21/1/01; aceito em 11/5/01

\begin{abstract}
ENZYMELESS BIOSENSORS: A NOVEL AREA FOR THE DEVELOPMENT OF AMPEROMETRIC SENSORS. The aim of this work is to describe the recent area that it has been developed for the construction of amperometric sensors, with the purpose to make possible a more effective electron transfer between enzyme and electrode. The advances reported in the literature will be described, such as enzymatic configurations that can be mimic using the chemistry of the artificial enzymes.
\end{abstract}

Keywords: enzymeless biosensors; electron transfer; modified electrode.

\section{INTRODUÇÃo}

Durante décadas uma das principais preocupações na construção de biossensores amperométricos centralizou-se na velocidade de transferência de elétrons do sítio ativo da enzima para a superfície do eletrodo ${ }^{1-3}$. Isto põe-se claramente em evidência, quando observa-se todas as transformações através das quais os biossensores tem passado, a procura de uma maior seletividade e eficiência na transferência de elétrons. Os biossensores da primeira geração, baseados na eletroatividade do substrato ou produto da reação enzimática, apresentavam problemas de interferências devido à necessidade de potenciais muito altos ${ }^{4}$. Na tentativa de diminuir estes potenciais, surgiram os biossensores de segunda geração, onde o emprego de mediadores de elétrons, tinham como função o transporte (shuttling) de elétrons entre a enzima e o eletrodo ${ }^{4}$. Entretanto, esta configuração pode apresentar problemas de interferências, uma vez que, este arranjo pode facilitar também a transferência de elétrons proveniente de reações redox paralelas à reação entre a enzima e o substrato. Com o intuito de superar estes problemas, uma nova categoria de biossensores chamada de terceira geração tem sido proposta a menos de uma década ${ }^{4}$. Esta é baseada na transferência direta de elétrons entre enzima e eletrodo na ausência de mediadores, sendo esta uma característica que a torna bastante vantajosa, já que promove uma maior seletividade, a medida que eles operam em potenciais mais próximos ao da própria enzima, diminuindo como consequiência reações interferentes, assim como, dispensando o uso de outros reagentes na sequiência das reações enzimáticas. Grupos de pesquisas têm publicado que uma transferência de elétrons eficiente é conseguida, através de uma diminuição ou remoção da camada protetora de proteínas ao redor do sítio ativo da enzima, sem perder a seletividade e ao mesmo tempo aumentando a sensibilidade oferecida pelos "biossensores" construídos desta forma.

Neste sentido, o trabalho desenvolvido por Lötzbeyer e colaboradores ${ }^{5,6}$ se faz bastante interessante já que eles compararam a enzima HRP (horseradish peroxidase) nativa com a mini-enzima MP-11 (micro peroxidase 11) e a hemina, ambas fragmentos do citocromo $c$ (Figura 1), concluindo que:

(i) A concentração de sítios ativos pode aumentar significativamente, comparada com enzimas grandes, quando mini-enzimas são

\footnotetext{
* e-mail: kubota@iqm.unicamp.br
}

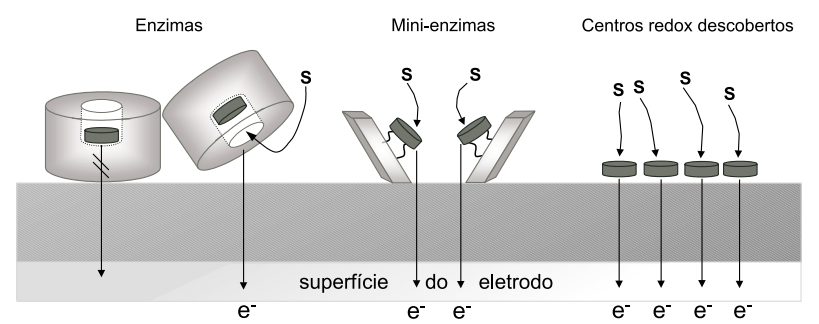

Figura 1. Representação esquemática demostrando as diferentes propriedades de eletrodos de ouro modificados com enzimas, mini-enzimas e grupos prostéticos, com relação à facilidade de acesso do substrato $(S)$ ao sítio ativo e à distância para transferência dos elétrons.

imobilizadas na forma de monocamada na superfície de um eletrodo de ouro.

(ii) A diferença na velocidade de transferência de elétrons entre a MP-11 e hemina claramente demostraram que moléculas menores permitem uma aproximação maior do sítio ativo (sistema ferro-porfirina) para o eletrodo, levando a um aumento na atividade eletrocatalítica.

(iii) Uma transferência de elétrons pode ser conseguida para enzimas grandes como HRP ou citocromo $c$ somente quando houver ao menos uma orientação parcial do sítio ativo em direção à superfície do eletrodo. Neste caso a difusão do substrato para o sítio ativo pode ser impedida por uma camada de proteína grande quando comparada com os biocatalisadores menores.

Desta forma, o melhor funcionamento dos biossensores amperométricos, dependerá da facilidade da transferência de elétrons do sítio ativo da enzima para a superfície do eletrodo, ficando bastante clara a possibilidade de construção de biossensores amperométricos sem a necessidade de imobilizar a enzima como um todo. Portanto, tentar imobilizar adequadamente num eletrodo, o sítio redox de uma enzima ou substâncias redox que exibam atividade catalítica para moléculas importantes, com a mesma função da enzima, seria importante na construção deste tipo de biossensores.

Estas são as bases para o desenvolvimento de uma nova área de biossensores amperométricos chamados de enzymeless biosensors ou biossensores sem enzimas, cujo objetivo é promover um aumento na transferência eletrônica entre eletrodo-sítio ativo-substrato, e desta forma aumentar a sensibilidade do sistema e a facilidade de constru- 
ção de sensores para determinação de substâncias biológicas de interesse. $\mathrm{O}$ aumento da estabilidade dos biossensores promovida por estas estratégias também é de suma importância para torná-los mais práticos.

Um pré-requisito fundamental para o desenvolvimento dos enzymeless biosensors é o controle do processo de transferência de elétrons entre o reagente que efetua o reconhecimento catalítico, aquele que faz a função do sítio ativo da enzima e a superfície do eletrodo. Desta forma, conceitos e estratégias para a construção deste tipo de sensores estão baseados na estrutura do sítio ativo da enzima tomada como base para a determinação do substrato em questão e o mecanismo da reação que será catalisada. Dentre os avanços científicos que podem vir a ser empregados no desenvolvimento de enzymeless biosensors, destaca-se a química biomimética de enzimas $\operatorname{artificiais}^{7-9}$.

\section{QUÍMICA BIOMIMÉTICA DE ENZIMAS ARTIFICIAIS}

Embora este artigo queira destacar basicamente a linha de pesquisa da química biomimética que está relacionada ao reconhecimento de substratos enzimáticos através de enzimas artificiais com a finalidade de mostrar aplicação na construção de enzymeless biosensors, cabe ressaltar que, a química biomimética oferece também a possibilidade de síntese de modelos simples para o reconhecimento de todas as outras classes de "substratos", isto é, cátions, ânions, espécies orgânicas e inorgânicas ${ }^{10,11}$. Para um melhor esclarecimento podem ser consultados os artigos publicados pelo trio ganhador do Prêmio Nobel de Química de 1987 Cram $^{10}$, Lenh ${ }^{11}$ e Pendersen ${ }^{12}$. Destacando-se às estruturas hospedeiras (host) tridimensionais criptanos ${ }^{10} \mathrm{e}$ éteres coroa ${ }^{12}$, que se ligam seletivamente a moléculas hóspedes (guest).

Sabe-se que as enzimas são estruturas complexas existentes em organismos vivos, que possuem grupos catalíticos e muitas vezes requerem de cofatores específicos ou coenzimas para desempenhar a catálise bioquímica, que é muitas vezes a força motora da existência desses organismos. Esta catálise enzimática altamente efetiva, existente na natureza, tem inspirado muitos pesquisadores a tentar imitála, há quase meio século quando $\mathrm{Cram}^{10}$ percebeu que as estruturas enzimáticas, altamente complexas, poderiam ser substituídas por compostos mais simples. O campo no qual estas tentativas situam-se é o da Química biomimética, ${ }^{7,8}$, em particular, das Enzimas Artificiais ${ }^{9}$. Cabe ressaltar que a idéia do uso de enzimas artificiais não está diretamente relacionada com a estrutura de enzimas naturais, mas sim com estruturas capazes de realizarem catálises de espécies importantes.

Na construção de enzymeless biosensors pode-se aproveitar compostos que vários grupos de pesquisa no mundo têm proposto e que podem apresentar comportamento de enzimas, compostos estes sintetizados em laboratórios e que são capazes de simular funções catalíticas enzimáticas.

Com a finalidade de sintetizar enzimas artificiais muitas configurações têm sido propostas. Pesquisadores têm partido desde a modificação de coenzimas ou cofatores naturais das enzimas, até a síntese de compostos que se apresentam como modelos enzimáticos. No primeiro caso, realiza-se a modificação de cofatores ou coenzimas, que normalmente são solúveis em meio aquoso, com a finalidade de torná-los hidrofóbicos e criar um ambiente mais adequado para a interação com o substrato. Entre esses cofatores pode-se mencionar as vitaminas $\mathrm{B}_{1}, \mathrm{~B}_{6}$ e $\mathrm{B}_{12}{ }^{13,14}$, o anel hemina ${ }^{7,13}, \mathrm{o} \mathrm{NADH}^{13,15}$ e as flavinas $^{13,16}$.

As enzimas também podem ser simuladas fazendo uso da química supramolecular ${ }^{11}$, com a qual catalisadores baseados neste tipo de estruturas podem executar os mesmos processos realizados pelas enzimas, sem seguir estritamente o caminho pelo qual as enzimas realmente o fazem. Sendo assim, esta química pode desenvolver compostos que efetuem processos altamente eficientes e seletivos em condições nas quais as enzimas denaturam. Dentre os compostos macrocíclicos mais usados para a síntese de enzimas artificiais temos os ciclofanos ${ }^{13,17}$, ciclodextrinas $(\mathrm{CD})^{13,18-21}$, micelas ${ }^{13,22} \mathrm{e}$ bicamadas moleculares ${ }^{23}$, em alguns casos enxertados com metais de transição, para permitir a catálise do substrato, através de reações redox, tentando imitar o centro ativo das metalo-enzimas. Em outros casos, esses compostos macrocíclicos, como as CD, são ligados covalentemente a cofatores enzimáticos, como fragmentos de vitaminas e flavinas, para obter a enzima artificial, com a porção catalítica fornecida pelo cofator e, o sítio de ligação hidrofóbico que permite a incorporação do substrato, fornecido pela macromolécula (Figura 2).

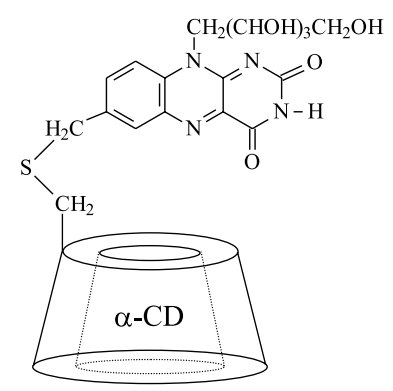

Figura 2. Estrutura de uma enzima artificial ${ }^{13}$ sintetizada ligando covalentemente um fragmento de flavina (porção catalítica) na posição de uma hidroxila primária de uma $\alpha$-CD (ciclo formado por seis moléculas de glicose) que funciona como sítio de ligação hidrofóbica para o substrato.

Pode-se verificar que são muitas as possibilidades de síntese das enzimas artificiais e por isso tem sido de interesse de químicos e bioquímicos durante várias décadas. Fundamentalmente, porque são modelos relativamente simples desses catalisadores bioquímicos naturais, apresentando seletividade e aumentando a velocidade da reação. Suas aplicações potenciais têm incentivado pesquisadores, porque se espera que sejam estáveis sob condições de mudanças de temperatura, $\mathrm{pH}$ e composição da solução, as quais frequentemente denaturam ou inativam os biocatalisadores naturais.

Dentre as áreas em potencial de aplicação para estas enzimas artificiais pode-se citar a área de enzymeless biosensors com transdução amperométrica, devido às óxido-redutases artificiais bem relatadas na literatura. Entretanto, para o desenvolvimento de enzymeless biosensors deve-se procurar imitar enzimas que gerem transferência de elétrons na presença de substratos que sejam de interesse analítico, isto é, de importância clínica, ambiental ou industrial. Neste sentido, apenas alguns exemplos de enzimas artificiais, que poderiam ser usadas ou que serviram como ponto de partida para a construção deste tipo de sensores, têm sido relatadas na literatura. Por outro lado, um conhecimento adequado da química de algumas metalo-enzimas, poderá auxiliar na procura de compostos simples, que possam substituir o sítio ativo redox dessas enzimas.

\section{Configurações baseadas em compostos macrocíclicos e/ou cofatores enzimáticos}

Recentemente, Schreyer e Mikkelsen ${ }^{24}$, divulgaram a síntese de uma cisteína oxidase artificial, a qual apresentou atividade para a oxidação dos tióis, cisteína e glutationa. Esta enzima artificial consiste de um anel $\beta$-Ciclodextrina ( $\beta-C D$, formado por 7 moléculas de glicose) no qual foi ligado covalentemente um grupo derivado do 
ferroceno, habitualmente usado como mediador de elétrons na construção de biossensores enzimáticos de segunda geração ${ }^{25}$. A ligação do ferroceno na posição de uma hidroxila secundária da $\beta$-CD foi feita através de um agente ligante etilenodiamino (Figura 3). Na determinação de tióis, o ferroceno previamente oxidado promove a oxidação do substrato (tiol) voltando ao seu estado natural reduzido, segundo o mecanismo abaixo:

$$
\begin{aligned}
& \beta \text {-CD-Ferroceno } \rightarrow \beta \text {-CD-Ferricinium }+\mathrm{e}^{-} \\
& \beta \text {-CD-Ferricinium }+\mathrm{R}-\mathrm{SH} \rightarrow \beta-\mathrm{CD}-\text { Ferroceno }+\mathrm{R}-\mathrm{S} \bullet+\mathrm{H}^{+} \\
& \text {2R-S• } \rightarrow \text { R-S-S-R }
\end{aligned}
$$

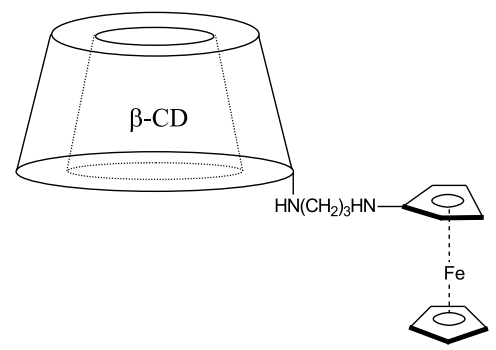

Figura 3. Estrutura da cisteína oxidase artificial, mostrando a $\beta$-CD ligada à molécula de ferroceno, através do agente ligante etilenodiamino.

Os estudos mostraram que a corrente eletrocatalítica de oxidação aumenta linearmente com o aumento da concentração de cisteína na cela de medida, seguindo a cinética de Michaelis-Menten.

Ao serem comparadas as constantes de oxidação da cisteína e glutationa, na presença da enzima artificial (ferroceno ligado à $\beta$ CD) e na presença do ferroceno livre, os valores obtidos para cada substrato foram respectivamente de 137 (em pH 8,0) e 2,4 (em pH $7,0)$ vezes maiores àqueles obtidos usando apenas ferroceno. Este fato mostrou que a ligação de ferroceno na $\beta-C D$ favorece a oxidação dos tióis. Neste sentido a $\beta$-CD fornece o sítio hidrofóbico para hospedar o tiol, e o ferroceno faz as vezes de sítio ativo, onde ocorre a transferência de elétrons.

Aproveitando o uso dos derivados de ferroceno ligados a ciclodextrinas, Suzuki e colaboradores ${ }^{26}$, ligaram ferroceno na $\beta-C D$ na posição de uma hidroxila, enquanto que as hidroxilas remanescentes foram acetiladas (Figura 4) com a finalidade de permitir sua dissolução em meio orgânico. Esta enzima artificial mostrou oxidação seletiva com maior eficiência na catálise de álcool benzílico e 1naftaleno-metanol, em acetonitrila, quando comparada à catálise obtida usando ferroceno livre e $\beta-\mathrm{CD}$.

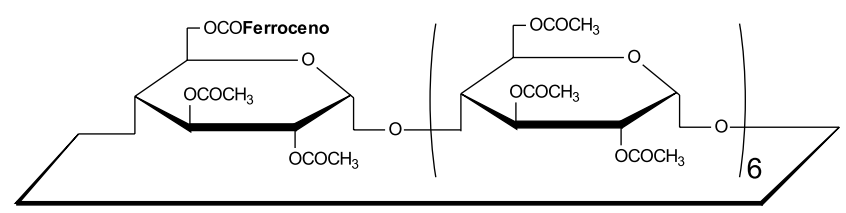

Figura 4. Representação esquemática da enzima artificial para determinação de álcoois em meio orgânico.

O mecanismo proposto pelos autores para a oxidação dos álcoois é mostrado na Figura 5. Inicialmente, em meio orgânico, o ferroceno pode estar acomodado na cavidade hidrofóbica da $\beta-C D$, quando o ferroceno sofre oxidação, o cátion ferricinium sai da cavidade hidrofóbica e a deixa livre para que outra substância (o substrato) possa ingressar, formando-se um complexo intermolecular, entre o ferroceno oxidado e o substrato, que facilita a transferência eficiente de elétrons devido à distância entre eles ser curta, já que a posição das duas espécies é rígida. Desta forma, o substrato oxidado é excluído da cavidade hidrofóbica da $\beta$-CD, permitindo a re-colocação do ferroceno, regenerado pela transferência eletrônica.

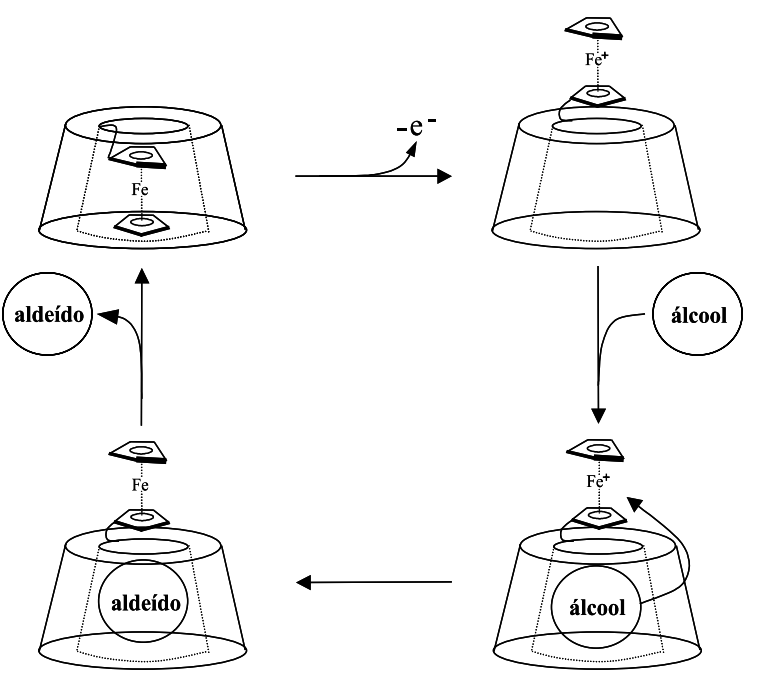

Figura 5. Mecanismo para a oxidação de álcoois em meio orgânico proposto por Suzuki e colaboradores ${ }^{26}$.

Outra configuração interessante que poderia ser usada na construção de enzymeless biosensors, baseia-se nas enzimas que usam como cofator flavinas. Neste sentido, Ye e colaboradores tem publicado vários trabalhos ${ }^{27,28}$ mostrando a síntese e eficiência de enzimas artificiais à base de flavinas e que foi empregada na catálise eficiente de tióis. Para isto, derivados de flavina foram ligados covalentemente a 2-metil [7 $\alpha-o-10$-metil-7-isoaloxazina]- $\beta-\mathrm{CD}$, representada por 2 -fl $\beta C D$. Os resultados mostraram que em atmosferas isentas de ar houve redução da flavina e oxidação do substrato (fenilmetanotiol), e que a $2-\mathrm{fl} \beta \mathrm{CD}$, foi reoxidada em contato com o ar. Estudos de química computacional ${ }^{29}$ mostraram que o complexo substratoenzima artificial (2-flßCD), que favorece a redução da flavina (Figura 6) é bastante estável. Esses mesmos estudos computacionais sugerem que na oxidação de tióis a dissulfetos pela flavina oxidada, os tióis adicionam-se ao carbono da posição 4 das flavinas oxidadas, produzindo um aduto. A reação de uma segunda molécula de tiol no aduto gera o dissulfeto e a flavina reduzida, tal como mostrado no Esquema a seguir:

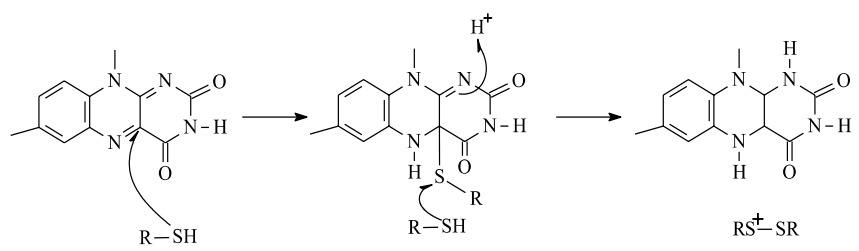

Outra idéia bastante interessante diz respeito às sínteses de coenzimas artificias, análogas ao NADH, na catálise de álcoois. Esta idéia foi recentemente publicada por Ansell e colaboradores ${ }^{30}$, que mostraram o uso de um composto mais estável e barato que o NADH. Trata-se do composto CL4 o qual compreende uma fração nicotinamida acoplada via um anel de triazina, a uma unidade dibenzenossulfônica (Figura 7). Entre as desidrogenases que apre- 


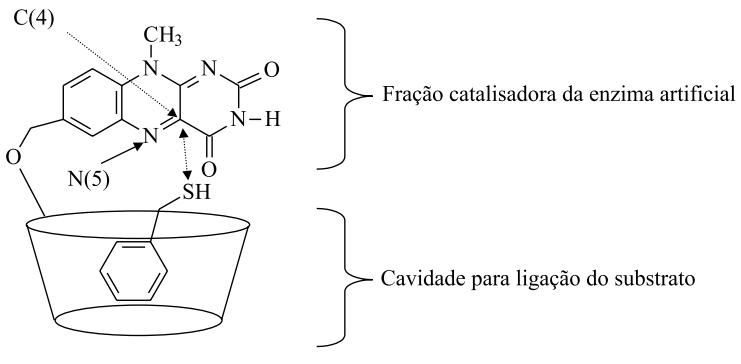

Figura 6. Esquema do complexo produzido entre a enzima artificial 2fl $\beta C D$ e o fenilmetanotiol.

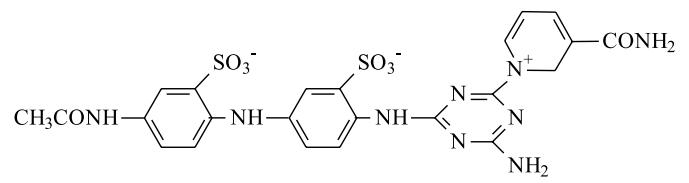

Figura 7. Estrutura química do composto CL4 que apresenta propriedades de coenzima para desidrogenases.

sentaram atividade usando este cofator artificial ou seus análogos estiveram, a glicose desidrogenase do Basillus megaterium, glicose-6fosfato desidrogenase de Leuconostoc mesenteroides e sorbitol desidrogenase de fígado de ovelha. Na presença de álcool desidrogenase de fígado de cavalo e um dos análogos de CL4 obteve-se catálise para butanol.

Dos trabalhos anteriormente relatados pode-se concluir que de fato a área de enzimas artificiais pode ser aplicada na construção de enzymeless biosensors satisfatoriamente abrindo um amplo campo de pesquisa a ser explorado.

\section{Configurações baseadas na química das metalo-enzimas}

Na catálise de álcoois, a enzima álcool desidrogenase é uma das desidrogenases que utilizam íon zinco no sítio ativo do grupo catalítico. Esta enzima catalisa a transferência de um hidreto da coenzima NADH, a uma grande variedade de aldeídos alifáticos e cetonas. Vários mecanismos têm sido propostos para sua ação catalítica, muitos deles incluindo a interação do oxigênio carboxílico do substrato coordenado ao átomo de zinco, onde este atuaria como um ácido de Lewis recebendo a densidade eletrônica. Conseqüentemente, muitos esforços têm sido direcionados para elucidar o papel do zinco e outros íons metálicos em modelos de reação enzimática. Também é bastante conhecido que essa coordenação direta do zinco das desidrogenases com os grupos carboxílicos e hidroxilas de substratos, tem sido diretamente relacionado com o fragmento 1,4dihidronicotinamida, tal como mostrado a seguir na equação $4^{15}$ :<smiles>[Y]N1C=CCC(C(N)=O)=C1</smiles>

Neste sentido, grupos de pesquisa têm tentado ligar estes fragmentos de NADH, ou modelos mais simples, a compostos capazes de complexar íons metálicos, tais como $\mathrm{Zn}$, com a finalidade de promover a formação do composto ternário, tal como ocorre na reação enzimática, sem a necessidade de usar a molécula de NADH, instável e de alto custo. Por exemplo, o grupo de Engbersen ${ }^{31}$, sintetizou moléculas com fragmentos de NADH ligados a fenantrolina, que serve como quelante do íon metálico, e que promove uma posição fixa do íon com o grupo nicotinamida, imitando o que acontece no sítio ativo da álcool desidrogenase, onde é gerada uma interação entre o íon metálico com o grupo dihidronicotinamida, através de interações de van der Waals. Neste caso, a função desempenhada pelo íon metálico ligado ao núcleo de fenantrolina, é a de um molde para ligar, orientar e ativar o substrato apropriadamente para sua redução dentro do complexo ternário. O 2-carboxialdeidopiridina ( $\mathrm{PyCHO}$ ), foi empregado como substrato e nenhuma interferência dos isômeros 3 e 4-PyCHO foi observada. $\mathrm{O}$ mecanismo proposto neste caso se baseia na transferência de hidreto na presença do íon $\mathrm{Zn}$ para gerar o correspondente álcool, seguido da redução da porção nicotinamida da enzima artificial proposta (Figura 8), da seguinte maneira: o íon metálico liga-se ao grupo fenantrolina e interage com o nitrogênio e/ou o sistema $\pi$ da porção dihidronicotinamida; na presença do substrato, o carbono no qual ocorrerá a redução, forma um complexo ternário no qual a transferência de hidreto ocorre.

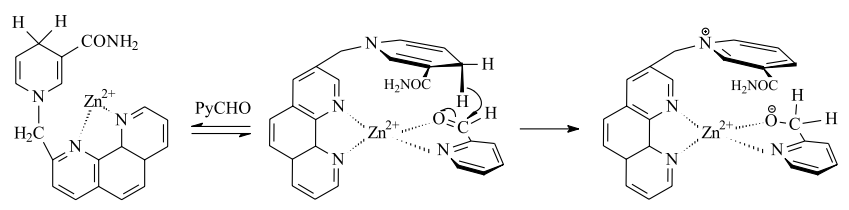

Figura 8. Mecanismo da transferência do hidreto da nicotinamida, para promover a redução do $\mathrm{PyCHO}$, na presença do íon zinco.

As enzimas dependentes de cobre são vitais para o funcionamento dos organismos vivos e, é por isto que a literatura a respeito deste tópico é vasta. Por exemplo, a enzima citocromo oxidase contendo $\mathrm{Cu} / \mathrm{Fe}$, funciona na fosforilação oxidativa, catalisando a redução final de oxigênio molecular para água acoplado à formação de $\mathrm{ATP}^{32}$. O cobre também é especialmente importante no sistema nervoso central de eucariotes de ordem superior, aparecendo em proteínas responsáveis pela biogênese dos neurotransmissores catecolaminas e hormônio peptídico ${ }^{33}$.

Na última década esforços têm sido realizados para entender como funcionam as enzimas dependentes de cobre que empregam oxigênio para a funcionalização de substratos orgânicos. Estas podem ser classificadas segundo a maneira como o centro de cobre se envolve na funcionalização do substrato. Se a funcionalização é realizada utilizando somente um átomo de cobre, é chamada de enzima dependente de cobre mononuclear ${ }^{33}$. Entre elas, encontram-se a dopamina $\beta$-monooxigenase (D $\beta M$ ), a peptidilglicina $\alpha$-amidase (PAM), as cobre amino oxidases (CAOs) e a galactose oxidase (GO). Se, para a funcionalização é necessária a formação de um complexo de substrato com vários íons cobre, a enzima é chamada de bi- ou polinuclear ${ }^{34}$, entre as quais temos, a tirosinase, a lacase, a ascorbato oxidase e a ceruloplasmina.

Com base na ampla informação existente na literatura à respeito das enzimas dependentes de cobre, alguns autores ${ }^{35-37}$ têm desenvolvido sistemas sensores, onde toda a estrutura enzimática pode ser substituída por um complexo de cobre mais simples. No trabalho desenvolvido por Hasebe e colaboradores ${ }^{35}$, foi usado o complexo de poli-histidina de cobre, como espécie catalisadora, na construção de um enzymeless biosensor com transdução amperométrica para determinação de ascorbato. Este sensor apresentou um perfil de resposta seguindo a cinética governada pela equação de MichaelisMenten, que fez possível o cálculo da constante cinética de Michaelis - Menten $\left(\mathrm{K}_{\mathrm{M}}\right)$ do sistema. Desta forma, pode-se dizer que o catalisador conseguiu imitar o sítio ativo da enzima ascorbato oxidase. 
Em alguns casos trabalhos desenvolvidos no grupo de Kubota ${ }^{36,37}$ membrana de EVA (acetato de vinil etileno) dopada com íons $\mathrm{Cu}^{2+}$, têm sido usada para construir enzymeless biosensors com detecção potenciométrica. Mostrando catálise eficiente para ácido ascórbico ${ }^{36}$ e dopamina ${ }^{37}$.

Desta forma com base nestes trabalhos mostrados pode-se observar que sistemas enzimáticos complexos, no caso particular das metalo-enzimas, podem ser substituídos satisfatoriamente por moléculas mais simples, contendo o metal que faz parte do sítio ativo da enzima, na construção de enzymeless biosensors.

Cabe ressaltar, que a existência de muitos tipos de metalo-enzimas e as inovações com as novas descobertas nos mecanismos envolvidos na catálise deste tipo de enzimas, é possível aproveitar a química de enzimas dependentes de metais tais como molibdênio ${ }^{38}$, manganês ${ }^{39}$, tungstênio ${ }^{40}$, ferro (não hemino) ${ }^{41,42}$, entre outros, na construção de enzymeless biosensors. Fornecendo ao pesquisador um amplo leque de possibilidades para ser explorado.

\section{ENZYMELESS BIOSENSORS DESCRITOS NA LITERATURA}

A construção de enzymeless biosensors sendo um campo de pesquisa ainda novo e incipiente, a literatura a respeito ainda é escassa. Entretanto, os poucos trabalhos reportados na literatura, procuraram demonstrar que imobilizando adequadamente substâncias inorgânicas simples ou complexos de metais de transição, capazes de catalisar substratos importantes da mesma forma que a enzima correspondente, torna possível a construção de enzymeless biosensor com detecção amperométrica, com suficiente seletividade, que pode ser avaliada através do cálculo de $\mathrm{K}_{\mathrm{M}}$, e ao mesmo tempo apresentando maior sensibilidade.
A Tabela 1 mostra os enzymeless biosensors descritos na literatura. Pode-se observar que muitos deles apresentam faixas de resposta da ordem de $\mu \mathrm{mol} \mathrm{l}^{-1}$, demonstrando claramente que havendo um contato mais eficiente entre o catalisador (enzima artificial) e o eletrodo, sensibilidade maiores podem ser obtidas. Como exemplo pode-se citar o enzymeless biossensor para dopamina reportado por Angnes e colaboradores $^{43}$ que apresenta resposta da ordem de $110^{-7} \mathrm{~mol} \mathrm{l}^{-1}$. Quando comparados com seus correspondentes biossensores, a base de enzima, a resposta obtida pelos enzymeless biosensors, em relação à afinidade, mostra que os valores obtidos para $\mathrm{K}_{\mathrm{M}}$ estão na ordem de mmol $1^{-1}$ que indica uma boa afinidade entre a espécie catalisadora e o substrato. Estes valores encontram-se na mesma ordem de grandeza desta constante quando calculada usando biossensores enzimáticos.

O desempenho analítico dos enzymeless biossensor, em alguns casos mostrou-se superior em relação aos correspondentes biossensores enzimáticos. No sensor desenvolvido por Zen et al. ${ }^{45}$ para determinação de hipoxantina $(\mathrm{Hx})$ usando complexo de $\mathrm{Ru}$, foi possível determinar $\mathrm{Hx}$, sem a interferência de ácido úrico e xantina, a diferença do que ocorre quando é usado biossensor a base de xantina oxidase. Já o sensor desenvolvido por Hasebe et al..$^{35}$ apresentou desempenho equivalente ao biossensor a base da enzima ascorbato oxidase, com a vantagem de não mostrar influência de $\mathrm{pH}$ na faixa entre 4 e 11, e um tempo de vida útil longo (maior que três meses). Este comportamento é conseqüência da ausência de material biológico na configuração do sensor.

Com isto, pode-se ter uma idéia do ganho que se pode conseguir com os enzymeless biosensors imobilizando adequadamente uma espécie redox que possa se comportar como uma enzima na catálise de substratos biológicos podendo-se obter desempenhos superiores àqueles mostrados pelos biossensores enzimáticos.

Tabela 1. Enzymeless biosensors relatados na literatura e suas principais características.

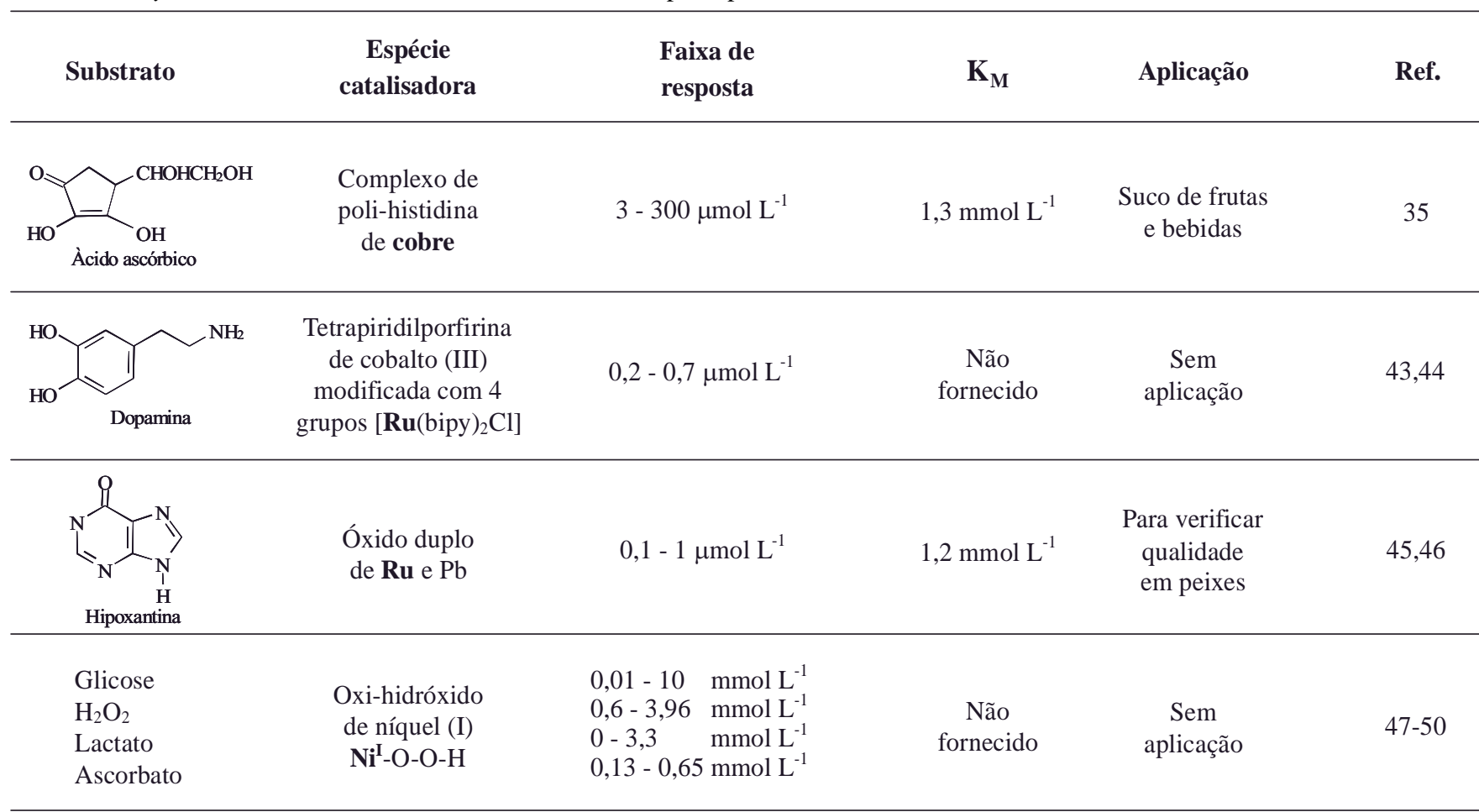

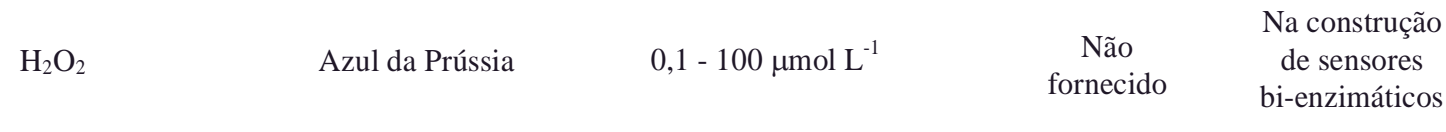




\section{CONCLUSÕES E TENDÊNCIAS}

Dos exemplos citados na literatura até o momento é importante ressaltar que um requisito para se desenvolver biossensores sem enzimas é o conhecimento profundo da química da interação entre a enzima e o substrato, isto permitirá tentar a síntese de pequenas moléculas catalisadoras que se comportem como enzimas com pequena massa molar. Entretanto, como se tem poucas enzimas com o comportamento bem conhecido, a maioria delas ainda encontra-se sob investigação, dificulta o desenvolvimento deste tipo de sensor. Por outro lado, tentativas de modificar eletrodos com compostos já conhecidos e de fácil aquisição, poderá possibilitar a construção de enzymeless biosensors, desde que apresentem uma resposta semelhante ao da catálise enzimática.

Desta forma, estudos relacionados com a utilização de moléculas pequenas que exibem atividade catalítica para a construção de sensores amperométricos para determinação de substâncias biológicas de interesse, ainda são raros. Assim a área de enzymeless biosensors é muito recente e incipiente, sendo um campo vasto a ser explorado. A química dos sítios ativos das metalo-enzimas pode ser aproveitada para o desenvolvimento de novos sensores para serem utilizados na análise de um grande número de substâncias biológicas.

\section{AGRADECIMENTOS}

Os autores agradecem o apoio financeiro recebido da Fundação de Amparo à Pesquisa do Estado de São Paulo (FAPESP).

\section{REFERÊNCIAS}

1. Schmidt, H.-L.; Gutberlet, F.; Schuhmann, W.; Sens. Actuators B 1993, 1314, 366 .

2. Liu H.; Ying, T.; Sun, K.; Li, H.; Qi, D.; Anal. Chim. Acta 1997, 344, 187.

3. Okawa, Y.; Nagano, M.; Hirota, S.; Kobayashi, H.; Ohno, T.; Watanabe, M; Bios. Bioelect. 1999, 14, 229.

4. Gorton, L.; Lindgren, A.; Larsson, T.; Munteanu, F.D.; Ruzgas, T.; Gazaryan, I.; Anal. Chim. Acta 1999, 400, 91.

5. Lötzbeyer, T.; Schuhmann, W.; Schmidt, H-L; Sens. Actuators B 1996, 33, 50.

6. Lötzbeyer, T.; Schuhmann, W.; Schmidt, H-L; Bioelect. Bioenerg. 1997, 42,1 .

7. Breslow, R.; Overman, L.E. J. Am. Chem. Soc. 1970, 92, 1075.

8. Breslow, R.; Acc. Chem. Res. 1980, 13, 170.

9. Breslow, R.; Acc. Chem. Res. 1995, 28, 146.

10. Cram, D.J.; Angew. Chem., Int. Ed. 1988, 27, 1009.

11. Lehn, J-M.; Angew. Chem., Int. Ed. 1988, 27, 89.

12. Pendersen, C.J.; Angew. Chem., Int. Ed. 1988, 27, 1021.

13. Murakami, Y.; Kikuchi, J.; Hisaeda, Y.; Hayashida, O.; Chem. Rev. 1996, 96, 721.

14. Hisaeda, Y.; Kihara, E.; Nishioka, T.; J. Inorg. Biochem. 1997, 67, 235.

15. Murakami, Y.; Aoyama, Y.; Kikushi, J.; J. Chem. Soc., Perkin Trans. I 1981, 11, 2809.

16. Kajiki, T.; Moriya, H.; Hoshino, K.; Kuroi, T.; Kondo, S.; Nabeshima, T.; Yano, Y.; J. Org. Chem. 1999, 64, 9679.

17. Walliman, P.; Mattei, S.; Seiler, P. Diederich, F.; Helv. Chim. Acta 1997, $80,2368$.
18. Bonchio, M.; Carofiglio, T.; Di Furia R.; Fornasier, R.; J. Org. Chem. 1995, 60, 5986.

19. Ikeda, H.; Horimoto, Y.; Nakata, M.; Ueno, A.; Tetrahedron Lett. 2000, $41,6483$.

20. Breslow, R.; Chmielewski, J.; Foley, D.; Johson, B.; Kumabe, N.; Varney, M.; Mehra R.; Tetrahedron 1988, 44, 5515.

21. Suh, J.; Noh, Y.S.; Bioorg. Med. Chem. Lett. 1998, 8, 1327.

22. Jairam, R.; Potvin, P.G., Balsky, S.; J. Chem. Soc., Perkin Trans. 2 1999, 2,363 .

23. Kikushi, J.; Zhang, Z.; Murakami, Y.; Chem. Lett. 1994, 8, 1559.

24. Schreyer, S.K.; Mikkelsen, S.R.; Bioconjugate Chem. 1999, 10, 464

25. Wang, J.; J. Pharm. Biomed. Anal. 1999, 19, 47.

26. Suzuki, I.; Chen, Q.; Kashiwagi, Y.; Osa, T.; Ueno, A.; Chem. Lett. 1993, 10, 1719.

27. Ye, H.; Tong, W.; D’Souza V.T.; J. Chem. Soc., Perkin Trans. 2 1994, 12 ,2431.

28. Ye, H.; Tong, W.; D'Souza V.T.; J. Am. Chem. Soc. 1992, 114, 5470.

29. Tong, W.; Ye, H.; Rong, D.; D'Souza V.T.; J. Comput. Chem. 1992, 13, 614

30. Ansell, R.J.; Small, D.A.P.; Lowe, C.R.; J. Mol. Catal. B: Enzym. 1999, 6,111 .

31. Engbersen, J.F.; Koudijs, A.; Plas, van der H.C.; J. Org. Chem. 1990, 55, 3647.

32. Miller, S. F.; Babcock, G.T.; Chem. Rev. 1996, 96, 2889.

33. Klinman, J.P.; Chem. Rev. 1996, 96, 2541.

34. Solomon, E. I.; Sundaram, U. M.; Machonkin, T. E.; Chem. Rev. 1996, 96, 2563.

35. Hasebe, Y.; Akiyama, T.; Yagisawa, T.; Uchiyama, S.; Talanta 1998, 47, 1139.

36. Fernandes, J.C.B.; Kubota, L.T.; Oliveira-Neto G.; Electroanalysis 1999, 11,475 .

37. Rover-Jr., L.; Fernandes, J.C.B.; Oliveira-Neto, G.; Kubota, L.T.; J. Electroanal. Chem. 2000, 481, 34.

38. Hille, R.; Chem. Rev. 1996, 96, 2757.

39. Dismukes, G.C.; Chem. Rev. 1996, 96, 2909

40. Johnson, M.K.; Rees, D.C.; Adams, M.W.W.; Chem. Rev. 1996, 96, 2817.

41. Que, L. Jr.; Ho, R.Y.N.; Chem. Rev. 1996, 96, 2607.

42. Costas, M.; Chen, K.; Que, L. Jr.; Coord. Chem. Rev. 2000, 200-202, 517.

43. Angnes, L.; Azevedo; C.M.B.; Araki; K.; Toma, H.E.; Anal. Chim. Acta 1996, 329, 91 .

44. Araki, K.; Angnes, L.; Azevedo, C.M.B.; Toma, H.E.; J. Electroanal. Chem. 1995, 397, 205.

45. Zen, J.-M.; Lai, Y.-Y.; Ilangovan, G.; Kumar, A.S.; Electroanalysis 2000, 12,280

46. Zen, J.-M.; Kumar, A.S.; Chang, M.-R.; Electrochim. Acta 2000, 45, 1691. 47. Berchmans, S.; Gomathi, H.; Rao, G. P.; Sens. Actuators B 1998, 50, 156.

48. Berchmans, S.; Gomathi, H.; Rao, G. P.; J. Electroanal. Chem. 1995, 394, 267.

49. Casella, I.G.; Desimoni,. E.; Salvi A.M.; Anal. Chim. Acta 1991, $243,61$.

50. Casella, I. G.; Cataldi T. R. I.; Salvi, A. M.; Desimoni, E.; Anal. Chem. 1993, 65, 3143.

51. Karyakin, A.A.; Karyakina, E.E.; Sens. Actuators B 1999, 57, 268.

52. Itaya, K.; Shoji, N.; Uchida, I.; J. Am. Chem. Soc. 1984, 106, 3423.

53. Karyakin, A.A.; Karyakina, E.E.; Gorton, L.; Talanta 1996, 43, 1597.

54. Cosnier, S.; Innocent, C.; Allien, L.; Poitry, S.; Tsacopoulos, M.; Anal. Chem. 1997, 69, 968.

55. Belay, A.; Ruzgas, T.; Csösegi, E.; Moges, G.; Tessema, M.; Solomon, T.; Gorton, L.; Anal. Chem. 1997, 69, 3471.

56. Villarta, R.; Cunningham, D.D.; Guilbault, G.G.; Talanta 1991, 38, 49.

57. Karyakin, A.A.; Karyakina, E.E.; Gorton, L.; J. Electroanal. Chem. 1998, $456,97$. 